\title{
South Africa's nutritional transition: Overweight, obesity, underweight and stunting in female primary school learners in rural KwaZulu-Natal, South Africa
}

\author{
N Tathiah, ${ }^{1}$ BSc (Hons), MB ChB, Dip HIV Man (SA), MS (Epi); I Moodley, ${ }^{1} \mathrm{PhD} ; \mathrm{V}$ Mubaiwa, ${ }^{2} \mathrm{MB}$ ChB, FCPHM (SA); \\ L Denny, ${ }^{3}$ MB ChB, MMed (O\&G), PhD, FCOG (SA); M Taylor, ${ }^{1}$ BSc (Pharm), MMedSci (Pharm), PhD (Comm Health) \\ ${ }^{1}$ Department of Public Health Medicine, University of KwaZulu-Natal, Durban, South Africa \\ ${ }^{2}$ Provincial Department of Health, Pietermaritzburg, KwaZulu-Natal, South Africa \\ ${ }^{3}$ Department of Obstetrics and Gynaecology, Faculty of Health Sciences, University of Cape Town, South Africa
}

Corresponding author: I Moodley (moodleyi15@ukzn.ac.za)

Background. Malnutrition substantially impacts the health outcomes of children. Globally, the childhood prevalence of overweight and obesity has increased, while underweight and stunting (though decreasing) continues to pose a major public health challenge. In low- to middle-income countries, a mixed pattern of over- and undernutrition (nutritional transition) can exist in communities.

Objective. To describe the prevalence of malnutrition among female learners in the Nongoma and Ceza districts in Zululand, KwaZuluNatal (KZN).

Methods. We performed a secondary analysis of anthropometric data collected during the 2011 HPV Vaccination Demonstration Project. School health teams, comprising trained nurses, measured the height (in $\mathrm{cm}$ ) and weight (in $\mathrm{kg}$ ) of 963 female learners in 31 primary schools. Internationally accepted standardised measures were used as cut-offs for defining overweight, obesity, underweight and stunting. Results. We found evidence of both under- and overnutrition. Overall, $9 \%$ of female learners were overweight, $3.8 \%$ obese, $4 \%$ underweight and 9.2\% stunted (using WHO/NCHS criteria). The highest levels of stunting were in the 11 - 12-year age groups, of underweight in the 10-year age group, of overweight and obesity in the 9 - 10-year age groups. Moreover, a proportion of underweight (17.4\%), overweight (11.1\%) and obese (22.9\%) learners were also stunted.

Conclusion. Our study describes the prevalence of overweight and obesity, wasting and stunting of female learners in KZN and suggests the presence of a nutritional transition in these rural communities; however, further studies are needed. Our findings emphasise the need for health promotion and education programs in schools.

S Afr Med J 2013;103(10):718-723. DOI:10.7196/SAMJ.6922

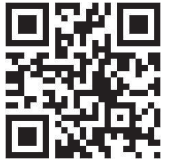

Malnutrition, which is defined as either undernutrition (underweight, wasting and stunting) or overnutrition (overweight and obesity) is a global public health challenge. ${ }^{[1]}$ In children, malnutrition has particularly significant health consequences during both early development and adulthood.

Overweight and obesity in children is on the rise globally. In 2011, 43 million (7\%) children under 5 years of age were overweight, an increase of 54\% from 28 million in 1990. ${ }^{[2]}$ Overweight and obesity have been linked to adverse psychological and physical outcomes during childhood and continuing into adolescence and adulthood. ${ }^{[3]}$ The association between overweight and obesity with psychosocial problems (anxiety, depression and negative self-image), health problems (diabetes and cardiovascular events) and impaired social, educational and economic productivity has been well documented. ${ }^{[3-5]}$ Moreover, childhood obesity is associated with a higher risk of adult obesity. ${ }^{[5]}$ Annually, 2.8 million adult deaths, and a substantial burden of non-communicable diseases, such as diabetes, ischaemic heart disease and cancer, are linked to overweight and obesity. ${ }^{\left[{ }^{[5]}\right.}$

Undernutrition continues to be a public health challenge globally, despite a decrease in prevalence. In 2011, 101 million (16\%) children under 5 years of age were underweight, 165 million (26\%) were stunted, and 52 million (8\%) were wasted. ${ }^{[2]}$ The majority (90\%) of the world's stunted children live in Africa and Asia. ${ }^{[2]}$ Undernutrition in childhood leads to underdevelopment and stunted growth, and is associated with higher morbidity and mortality. ${ }^{[1-3]}$ Underweight is also associated with low energy levels, tiredness and poor perceptions of body image. ${ }^{[1]}$

Patterns of malnutrition (both under- and overnutrition) are found in most low- to middle-income countries. Africa, notably, is home to the fastest overweight and obesity growth rates; the prevalence of overweight children increased from $4 \%$ in 1990 to $7 \%$ in $2011 .{ }^{[2,3]}$ South Africa (SA), a middle-income country, faces the burden of infectious diseases (such as HIV/AIDS and tuberculosis (TB)) existing alongside non-communicable diseases such as undernutrition, overnutrition, diabetes, hypertension and cancer. ${ }^{[5]}$ The rise of diet-related non-communicable diseases accounts for $28 \%$ of the burden of disease in $\mathrm{SA},{ }^{[6,7]}$ and is thought to be linked to the process of societal transition from a traditional rural lifestyle to the adoption of an urban way of life. ${ }^{[8,9]}$ This is generally accompanied by a 'nutritional transition', characterised by changes in patterns of consumption of food, alcohol and tobacco, reduction in physical activity, and a shift to a diet high in sugar, salt and trans-fats. ${ }^{[7-9]}$ Consequently, it is not uncommon to find evidence of undernutrition and overnutrition existing simultaneously in the same communities. ${ }^{[5]}$ Furthermore, it is also possible to encounter children, some of whom are overweight, alongside those who are stunted. This appears paradoxical, as stunting is due to an insufficient 
or unsuitable diet over the long term, while overweight is due to overnutrition. ${ }^{[10]}$ The aetiology, however, is complex, and is rooted in the inadequate nutrition received during the prenatal, infant and early childhood phases, combined with high-fat, energy-dense foods and a lack of physical activity. ${ }^{[3]}$ It has also been suggested that an impairment in fat oxidation may increase the susceptibility of stunted individuals to becoming overweight or obese. ${ }^{[3]}$

The South African National Youth Risk Behaviour (SANYRB) surveys were carried out in 2002 and 2008 with the majority of learners between 13 and 19 years of age (grades 8 - 11). ${ }^{[1,11]}$ The 2002 study reported that $16.9 \%$ of learners sampled were overweight and $4 \%$ were obese. ${ }^{[1]}$ Females were more likely to be overweight or obese than males. ${ }^{[1]}$ By 2008, the percentage of overweight learners had increased to $19.7 \%{ }^{[11]}$ The national prevalence of obesity was $5.3 \%$, with more obese female learners (7.2\%) than males (3.3\%). ${ }^{[11]}$ Among the provinces, KwaZulu-Natal (KZN) had the highest prevalence of overweight learners (25.5\%). ${ }^{[11]}$

SA ranks among the top 20 countries with the highest burden of undernutrition - approximately 1 in 10 children is underweight and 1 in 5 stunted - with higher levels in rural areas. ${ }^{[7]}$ Nationally, a comparison of the 2002 SANYRB with the 2008 data showed an overall decrease in the percentage of underweight learners ( $9 \%$ to $8 \%$ ), with more males than females. ${ }^{[1,11]}$ In the 2008 survey, $13 \%$ of learners were stunted, and $8 \%$ were wasted. ${ }^{[11]}$

Previous studies have highlighted the need to document the prevalence of malnutrition (overweight, obesity, underweight and stunting) in SA children. ${ }^{[4,12-14]}$ This study reports on the prevalence of overweight, obesity, underweight and stunting in female learners in 31 primary schools in rural KZN using anthropometric data collected during the Human Papilloma Virus (HPV) Vaccination Demonstration Project (HPVVDP), conducted in 2011. In this demonstration project, HPV vaccination was administered to learners by school health teams. The results of this paper have the potential to inform development strategies aimed at health promotion and education in school-going learners. ${ }^{[12]}$

\section{Objective}

To describe the prevalence of overweight, obesity, stunting and underweight among female learners in the districts of Nongoma and Ceza in Zululand, using data collected during the HPVVDP conducted in 2011.

\section{Methods}

This was a secondary analysis of anthropometric data collected during the HPVVDP in Zululand, SA during 2011. The method of data collection has been described in detail elsewhere. ${ }^{[15]}$

This study was approved by the institutional Human Research Ethics Committee at the University of Cape Town (UCT) and the KZN Provincial Department of Health (DoH). Written informed consent was obtained from the parents/caregivers of the learners prior to commencing vaccinations.

\section{Setting}

The project was located in Nongoma and Ceza, areas within the Zululand district of KZN. The Zululand district has an area of $14810 \mathrm{~km}^{2}$, with a population of 964005 people living in small isolated rural settlements or in 1 of 6 urban areas. ${ }^{[14]}$ The district is characterised by widespread poverty, high HIV incidence and poor access to basic services and facilities. Zululand, being a previously disadvantaged homeland area, reflecting its apartheid legacy, is one of the poorest regions in SA. ${ }^{[14]}$

\section{Study population}

A total of 963 HPVVDP vaccinated female learners ${ }^{[15]}$ from 31 schools (18 in Nongoma and 13 in Ceza) were chosen because of their proximity to clinics. The inclusion criteria for the HPVVDP were female learners between ages of 9 and 12 years. Exclusion criteria applied to learners who reported that they did not feel well, or did not have signed informed consent and those in whom, owing to administrative oversights during the registration process, some learners younger than 9 and older than 13 years were inadvertently vaccinated. All these latter criteria, although excluded from the HPV vaccination study, were included for the purposes of this anthropometric survey.

\section{Anthropometric measurements}

The school health teams of trained nurses were responsible for measurement and data collection. Learners were weighed (in $\mathrm{kg}$ ) without shoes and jerseys using an electronic digital scale, and height (in $\mathrm{cm}$ ) was measured using a stadiometer.

\section{Definition of measures}

- Underweight was defined as the proportion of learners with weight-for-age -2 Z-scores below the World Health Organization (WHO)/National Center for Health Statistics (NCHS) median. ${ }^{[1]}$

- Stunted learners were classified as such if the height-for-age cut-off value was $-2 Z$-scores below the WHO/NCHS median. ${ }^{[1]}$

- Overweight and obesity were defined using age and gender specific international cut-off points for body mass index (BMI) as defined by Cole et al. ${ }^{[16]}$ This method is used in children aged $2-17$ years, and is based on the adult overweight and obesity cut-offs of $25 \mathrm{~kg} / \mathrm{m}^{2}$ and $30 \mathrm{~kg} / \mathrm{m}^{2}$, respectively. ${ }^{[1,16]}$ By definition, learners classified as obese are also included in the overweight category.

\section{Data analysis}

Means and standard deviations were calculated using SPSS software, version 18.0. BMI, weight-for-age $Z$-scores (WAZ) and height-for-age $Z$-scores (HAZ) were calculated using WHO AnthroPlus software. ${ }^{[17]}$ The programme does not compute WAZ for children above 10 years of age because weight-for-age measurements are distorted by the pubertal growth spurt in this age group. ${ }^{[17]}$

\section{Results}

Table 1 is a summary of age and anthropometric data for the 959 learners who participated in the HPVVDP. ${ }^{[15]}$ There were missing age values for 4 learners who were excluded from the analysis.

Table 1. Anthropometric data for the study participants

\begin{tabular}{llll}
\hline & Mean & $N$ & $\mathbf{9 5 \%}$ CI \\
\hline Age (years), mean (range) & $9.88(7-14)$ & 959 & - \\
Height $(\mathrm{cm})$ & 135.80 & 959 & $135.18-136.41$ \\
Weight $(\mathrm{kg})$ & 30.13 & 957 & $29.69-30.58$ \\
BMI $\left(\mathrm{kg} / \mathrm{m}^{2}\right)$ & 16.27 & 953 & $16.08-16.47$ \\
HAZ & -0.22 & 959 & $-0.35-0.097$ \\
WAZ & -0.22 & 724 & $-0.31--0.12$ \\
BAZ & -0.44 & 953 & $-0.53--0.35$ \\
CI = confidence interval; BMI = body mass index; HAZ = height-for-age $Z$-score; \\
WAZ = weight-for-age $Z$-score; BAZ = BMI-for-age Z-score.
\end{tabular}


According to the $Z$-scores, 9.2\% of learners were classified as stunted and $4 \%$ as underweight. BMI-for-age $Z$-scores indicated obesity in $3.8 \%$ of learners (>2 standard deviations (SDs) above the median) (Table 2).

In those learners who were underweight (as defined by $Z$-scores), $17.4 \%$ were also stunted (see Table 3). For overweight learners, $11.1 \%$ were stunted, and for obese learners, $22.9 \%$ were stunted (Table 3 ).

Fig. 1 shows the prevalence of stunting, underweight, overweight and obesity in learners aged $8-12$ years. The highest percentage of stunted learners was in the 11 - 12-year age group. The 11-year age group had $13.8 \%$ of stunted learners $(n=152)$, and the 12 -year age group had $42.3 \%(n=71)$. More than half of the learners in the 13 - 14-year age group $(n=7)$ were stunted. Underweight learners were in the 9- and 10-year age groups, with $2.5 \%(n=356)$ and $6.1 \%$ $(n=326)$ underweight, respectively. The highest percentage (10.2\%) of overweight learners was in the 10-year age group $(n=324)$, followed by the 9 -year-olds $(9.3 \%, n=356)$. The highest percentage of obese learners was in the 12-year age group $(2.8 \%, n=71)$. For the 9$(n=356)$ and 10 -year-old $(n=324)$ age groups, obesity was the same in each of the age groups (2.5\%).

Table 4 shows findings from other SA studies in relation to nutritional status of school going children. The studies, though varying in terms of location (urban or rural), size of the sample, and measuring tools, show that under- and malnutrition is a concern among school children.

\section{Discussion}

This study provides evidence of both forms of malnutrition (underand overnutrition) among female learners in rural KZN. Overall, $9 \%$ of female learners were overweight, $3.8 \%$ were obese, $4 \%$ were underweight, and 9.2\% stunted (using WHO/NCHS criteria). In terms of age categories, the highest levels of stunting were in the 11 - 12-year age groups and underweight was highest in the 10-year age group. The highest levels of overweight and obesity were in the 9 - 10-year-old age groups. Moreover, $17.4 \%$ of those underweight were also stunted. Stunting was also present in $11.1 \%$ and $22.9 \%$ of overweight and obese learners, respectively. Previous studies that have reported these anthropometric measurements have shown a wide variation in findings (Table 4). Reasons for these variations include differences in measurement methods and study populations (age, gender, rural or urban).

For instance, in a study conducted by Puckree et al., ${ }^{[19]}$ using WHO criteria, it was reported that $66 \%$ of learners (aged $10-12$ years) were underweight and 5\% were overweight. However, this was in 6 public schools in an urban setting in eThekweni District, KZN. ${ }^{[19]}$ Toriola et al. ${ }^{[20]}$ in a study in rural Limpopo of learners aged 10 to 16 years, using US Centers for Disease Control and Prevention (CDC) cut-off points, described $11 \%$ of girls as being overweight compared with $9 \%$ in boys; obesity occurred more in boys (5.5\%) than in girls (4.4\%). Underweight was described in $4.6 \%$ of girls and $5.2 \%$ of boys. Jinabhai et al. ${ }^{[18]}$ in a nutritional study conducted in rural KZN primary schools, described obesity (3.1\%) in a cohort of 8- to 11-year olds (using $Z$-scores), with a BMI $>18.5$ in $8.4 \%$ (absolute range not allowing for age). Underweight was described in $0.4 \%$. Findings from Armstrong et al. ${ }^{[13]}$ from $5 \mathrm{SA}$ provinces, using BMI cut-off points in agreement with international standards, showed an obesity prevalence in primary school learners aged $6-13$ years of 3.2\% for boys and $4.9 \%$ for girls, and an overweight prevalence of $14.0 \%$ (boys) and $17.9 \%$ (girls).

There has been much debate about the measurement of overweight and obesity in children, in view of measures not being globally representative, and using cut-offs based on age, sex, height and pubertal status. ${ }^{[12]}$ Cole et al. ${ }^{[16]}$ in developing the internationally recognised BMI curves, have acknowledged that the data are not representative of children from Africa.

Our study has presented data from SA female primary school learners, with a view to contributing to existing information. Despite being limited only to the cohort that participated in the HPVVDP, our study provides valuable anthropometric data from female learners of a particular age range in the Zululand district. These data can be used to inform health promotion strategies and school feeding programmes among school learners in this area.

Taken together, the existence of underweight, stunting, overweight and obesity in this cohort of rural learners may reflect the presence of a nutritional transition. This is in contrast to the historical epidemiological and demographic transition, which describes the decline of undernutrition and infectious diseases and their replacement by an increase in non-communicable disease risk factors such as overweight and obesity. ${ }^{[5,6,8,9]}$

In countries undergoing transition, such as SA, China, Brazil and Mexico, the co-existence of under- and overnutrition may be expected, especially if there were previously high levels of childhood malnutrition ${ }^{[10]}$ A study of Chinese rural and urban schoolchildren has shown the prevalence of underweight being three times that of overweight. ${ }^{[10]}$ In rural Mexico, a study showed an overall prevalence

Table 3. Stunting among learners according to weight categories

\begin{tabular}{ll}
\hline & $\boldsymbol{n}(\%)$ \\
\hline Underweight $(n=86)$ & $15(17.4)$ \\
Overweight $(n=81)$ & $9(11.1)$ \\
Obese $(n=35)$ & $8(22.9)$ \\
*As defined by Z-scores &
\end{tabular}

Table 2. Anthropometric $Z$-scores for height, weight and BMI ${ }^{\star}$

\begin{tabular}{|c|c|c|c|c|c|}
\hline & \multicolumn{5}{|c|}{$n(\%)$} \\
\hline & -2 & -2 to -1 & -1 to 1 & 1 to 2 & $>2$ \\
\hline Height-for-age $(n=959)$ & $88(9.2)$ & $204(21.3)$ & $517(53.9)$ & $82(8.5)$ & $68(7.1)$ \\
\hline Weight-for-age $(n=724)^{\dagger}$ & $29(4.0)$ & $125(17.3)$ & $480(66.3)$ & $69(9.5)$ & $21(2.9)$ \\
\hline BMI-for-age $(n=952)$ & $84(8.8)$ & $197(20.7)$ & $555(58.2)$ & $81(8.5)$ & $36(3.8)$ \\
\hline
\end{tabular}



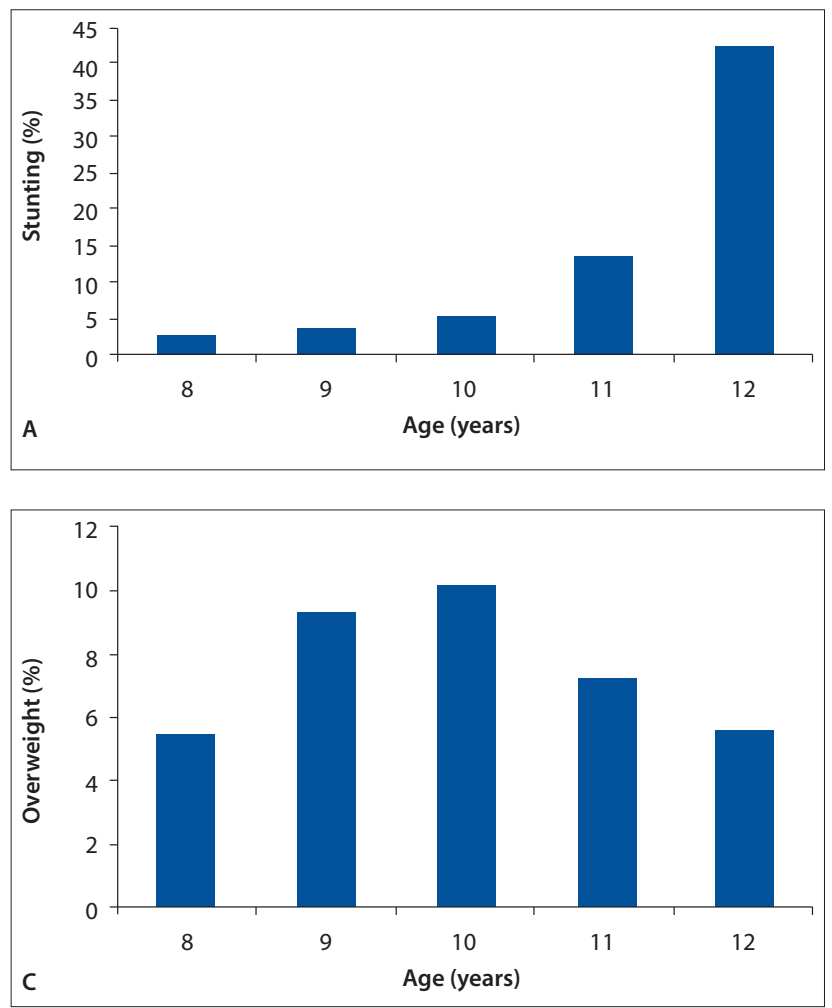

Fig. 1. Prevalence of A: stunting, B: underweight, C: overweight and D: obesity in learners aged $8-12$ years (as defined by international cut-off points for body mass index by Cole et al. $\left.{ }^{[16]}\right)$

of overweight/stunting of $20 \%$ and $10 \%$ stunting. ${ }^{[10]}$ Revealingly, many of these communities are characterised by children at risk of overweight/obesity playing alongside malnourished children. ${ }^{[10]}$ Of greater concern was the occurrence of overweight and stunting in the same child.

Evidence from a study in a rural Limpopo area shows that $19 \%$ of 3 -year-old children were found to be overweight and stunted. ${ }^{[10]}$ It was suggested that overweight was more likely to occur in higherincome families (having more money to spend on food) but, if true, stunting should have been decreased as well.

Factors that are associated with an increasing prevalence of overweight/obesity include increasing urbanisation and affluence, diets that are energy dense (more fat and animal protein), a more sedentary lifestyle, more time spent watching television and the availability of motor transport. ${ }^{[10,21]}$ Factors that are protective against increasing overweight include time spent in physical activity and hours of sleeping. ${ }^{[10,21]}$

The finding of underweight in rural learners indicates the presence of undernutrition in households and communities. ${ }^{[4]}$ Food insecurity is present in $35 \%$ of households, despite SA being a middle-income country. ${ }^{[4,22]}$ Apart from the quantity of food, the quality and diversity of food available to rural populations may also be a problem relating to food insecurity and undernutrition. ${ }^{[4]}$ The presence of HIV/AIDS, especially in women of child-bearing age, affects the ability of households to provide basic needs, ${ }^{[4,22]}$ the death of a mother being associated with a fourfold increase in child undernutrition. ${ }^{[4]}$

The SA National Development Plan (NDP) Vision for 2030, which focuses on the social determinants of health, recommends the eradication of child undernutrition aimed at improving school performance and increasing the likelihood of high school completion. ${ }^{[7]}$ The NDP highlights the need for healthy lifestyle and
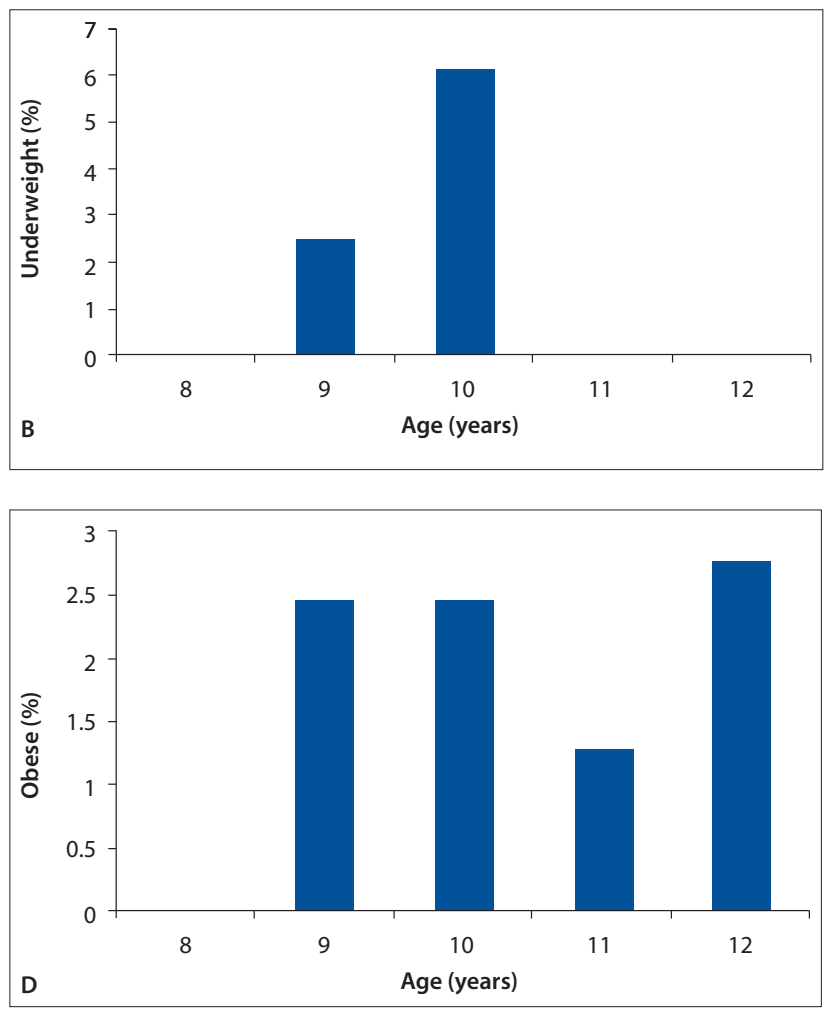

dietary options among learners, to reduce overweight and obesity, thereby preventing the onset of non-communicable diseases in adulthood. ${ }^{[7]}$ The role of appropriate nutrition in pregnant women is an important area of focus, owing to in utero factors that predispose children to stunting, underweight or overweight. ${ }^{[10]}$

The Integrated School Health Policy highlights the need for nutritional assessments, education and identification and referral of at-risk school learners. ${ }^{[22]}$ Since underweight, overweight and obesity are largely preventable, prevalence studies such as this can be used to develop strategies for health promotion or management in schools and communities, and as part of primary health care community programmes.

\section{Conclusion}

This study of female learners in Nongoma and Ceza in Zululand, $\mathrm{KZN}$, describes the prevalence of overweight and obesity, wasting and stunting. The observations in this study suggest the presence of a nutritional transition in these rural communities. Further studies are needed to confirm this observation. The need for health promotion and education programmes in the school context has been emphasised.

Acknowledgements. The authors acknowledge the members of the HPVVDP Working Group, MSD (Merck \& Co., SA), and the school health teams, the learners and their parents/caregivers, and community members for their participation in this project.

Authors' contributions. NT and IM participated in the implementation of the project, the evaluation of the results, and drafting of the manuscript. LD and VM conceived the study, and participated in its design and coordination and helped to draft the manuscript. MT helped to draft the manuscript. All authors read and approved the final manuscript. 


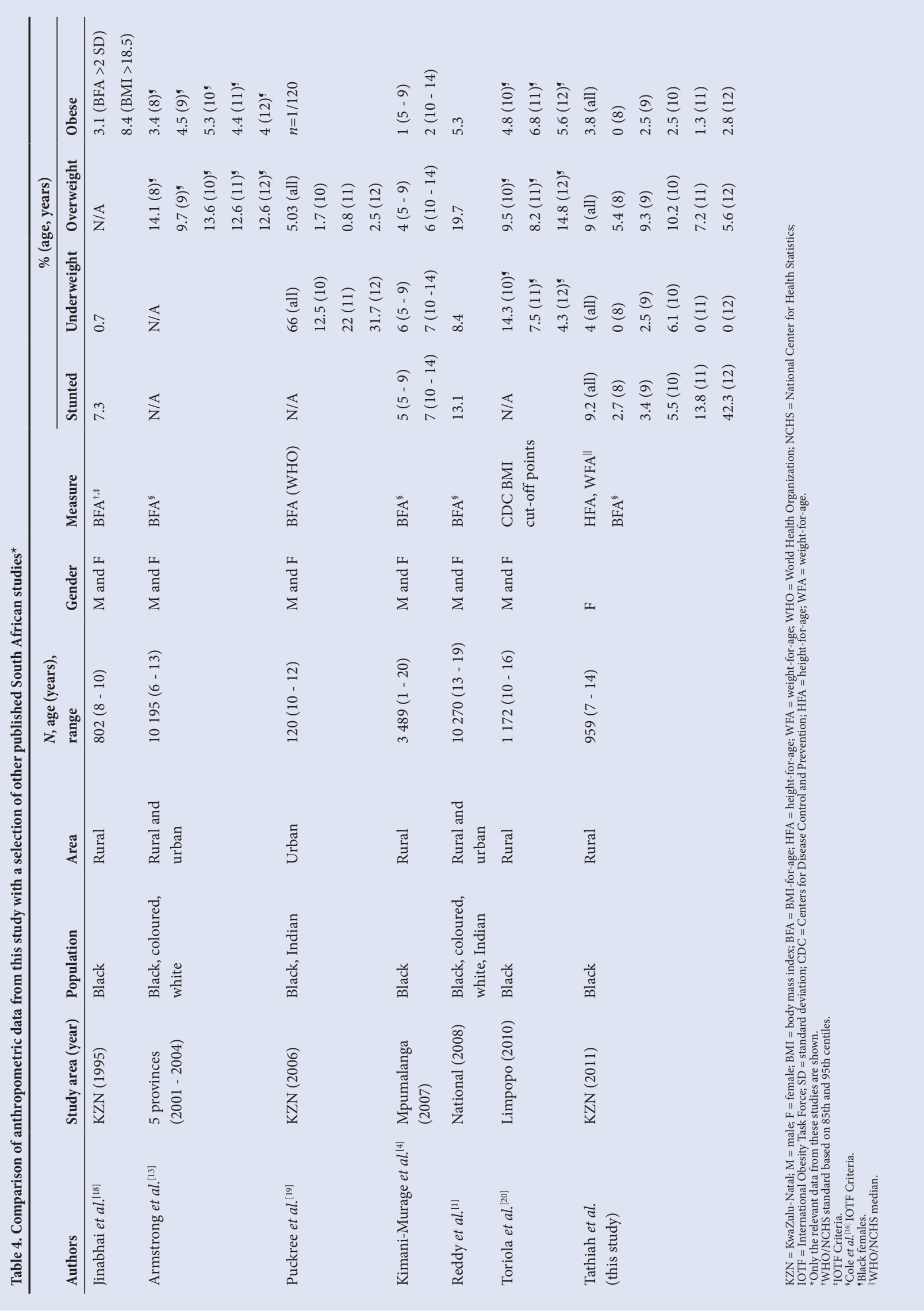




\section{References}

1. Reddy SP, Resnicow K, James S, Kambaran N, Omardien R, Mbewu AD. Underweight, overweight and obesity among South African adolescents: Results of the 2002 National Youth Risk Behaviour Survey. Public Health Nutrition 2009;12(2):203-207. [http://dx.doi.org/10.1017/S1368980008002656]

2. United Nations Children's Fund, World Health Organization, The World Bank. UNICEF WHO-World Bank: Joint Child Malnutrition Estimates. Geneva: WHO, 2012. http://www.who.int/nutgrowthdb/ estimates/en/ (accessed 20 May 2013).

3. Rossouw H, Grant C, Viljoen M. Overweight and obesity in children and adolescents: The South African problem. S Afr J Sci 2012;108(5/6). [http://dx.doi.org/10.4102/sajs.v108i5/6.907]

4. Kimani-Murage EW, Kahn K, Pettifor IM, et al. The prevalence of stunting, overweight and obesity Kimani-Murage EW, Kahn K, Pettifor JM, et al. The prevalence of stunting, overweight and obesity,
and metabolic disease risk in rural South African children. BMC Public Health 2010;10:158. [http:// dx doi.org/10.1186/1471-2458-10-158]

5. WHO. Obesity and Overweight. http://www.who.int/mediacentre/factsheets/fs311/en/ (accessed 17 October 2012)

6. Bradshaw D, Schneider M, Norman R, Bourne LT. Mortality patterns of chronic diseases of lifestyle in South Africa. In: Steyn K, Fourie J, Temple N, eds. Chronic diseases of lifestyle in South Africa. Tygerberg: Medical Research Council; 2006:58-64

7. National Planning Commission. National Development Plan: Vision for 2030. Pretoria: NPC, 2011 http://www.npconline.co.za/medialib/downloads/home/NPC\%20National\%20Development\%20 Plan\%20Vision\%202030\%20-lo-res.pdf (accessed 20 May 2013).

8. Vorster HEH. The link between poverty and malnutrition: A South African perspective. Health SA Gesondheid 2010;15(1). [http://dx.doi.org/10.4102/hsag.v15i1.435]

9. Food and Agriculture Organization of the United Nations. The double burden of malnutrition. Case studies from six developing countries. Rome: FAO, 2006. http://www fao org/docrep/009/20442e/ a0442e00.htm (accessed 20 May 2013).

10. Poskitt EM. Countries in transition: Underweight to obesity non-stop? Ann Trop Paediatr 2009;29(1):1-11. [http://dx.doi.org/10.1179/146532809X401971]

11. Reddy SP James S, Sewpaul R, et al Umthente Uhlaba Usamila - The South African Youth Risk Behaviour Survey 2008. Cape Town: South African Medical Research Council, 2010. http://www.mrc. Behaviour Survey 2008. Cape Town: South African Medical Research Coun
ac.za/healthpromotion/yrbs_2008_final_report.pdf (accessed 20 May 2013).

ac.za/healthpromotion/yrbs_2008_final_report.pdf (accessed 20 May 2013).
2. Jinabhai CC, Taylor M, Sullivan KR. Implications of the prevalence of stunting, overweight and obesity 2. Jinabhai CC, Taylor M, Sullivan KR. Implications of the prevalence of stunting, overweight and obesity
among South African primary school children: A possible nutritional transition? Eur J Clin Nutr 2003;57(2):358-365. [http://dx.doi.org/10.1038/sj.ejcn.1601534
13. Armstrong ME, Lambert MI, Sharwood KA, Lambert EV. Obesity and overweight in South African primary school children - the Health of the Nation Study. S Afr Med J 2006;96(5):439-444.

4. Zululand District Municipality. Draft Integrated Development Plan: 2012 - 2016. Zululand: Zululand District Municipality, 2012. http://www.zululand.org.za/media/3109/ZDM\%20Draft\%20IDP\%20 2012-2013_1.pdf. (accessed 20 May 2013).

15. Moodley I, Mubaiwa V Tathiah N, Denny L. High uptake of Gardasil vaccine among 9 - 12-year old schoolgirls participating in an HPV vaccination demonstration project in KwaZulu-Natal Province. S Afr Med J 2013;103(5):318-321. [http://dx.doi.org/10.7196/samj.6414]

16. Cole TJ, Bellizzi MC, Flegal KM, Dietz WH. Establishing a standard definition for child overweight and obesity worldwide: International survey. BMJ 2000;320(7244):1240-1243. [http://dx.doi.org/10.1136/ bmj.320.7244.1240]

17. Blössner M, Siyam A, Borghi E, Onyango A, de Onis M. WHO AnthroPlus for personal computers: Software for assessing growth of the world's children and adolescents. Geneva: WHO, 2009. http:// www.who.int/growthref/tools/who_anthroplus_manual.pdf (accessed 20 May 2013).

18. Jinabhai CC, Taylor M, Coutsoudis A, Coovadia HM, Tomkins AM, Sullivan KR. A health and nutritional profile of rural school children in KwaZulu-Natal, South Africa. Ann Trop Paediatr 2001;21(1):50-58.

19. Puckree T, Naidoo P, Pillay P, Naidoo T. Underweight and overweight in primary school children in eThekweni District in KwaZulu-Natal, South Africa. Afr J Prm Health Care Fam Med 2011;3(1). [http://dx.doi.org/10.4102/phcfm.v3i1.203]

20. Toriola A L, Moselakgomo VK, Shaw BS, Goon DT. Overweight, obesity and underweight in rural black South African children. S Afr J Clin Nutr 2012;25(2):57-61.

21. Tharkar S, Viswanathan V. Imact of socioeconomic status on prevalence of overweight and obesity among children and adolescents in India. The Open Obesity Journal 2009;1:9-14.

22. Department of Health, National Department of Basic Education. Integrated School Health Policy. Peartment of Health, National Department of Basic Education. Integrated School Health Policy.
Pretoria: DoH, 2012. http://www.doh.gov.za/docs/policy/2012/Integrated_School_Health_Policy.pdf (accessed 20 May 2013)

Accepted 20 May 2013. 